\title{
Estratégias defensivas contra o sofrimento psíquico entre trabalhadores
}

\author{
Wellington Lima Amorim, (D) I, A Ana Flavia Moura Carvalho, (DD II Rachel Vianna Leão (D) II \\ ${ }^{I}$ Universidade Federal do Rio Grande do Sul, Tramandai, RS, Brasil \\ ${ }^{I I}$ Universidade Federal do Maranhão, São Luís, MA, Brasil
}

\begin{abstract}
Resumo
O artigo propõe contribuir para a saúde mental dos trabalhadores. Para tanto, buscou-se, como pano de fundo, um breve contexto histórico do trabalho. A expansão do modelo capitalista, na segunda metade do século $X X$, acarretou um aumento progressivo do tempo e da dedicação ininterrupta ao emprego, o que repercutiu sobre a saúde do trabalhador. Este trabalho avaliou o perfil do trabalhador de sucesso, o sofrimento presente no contexto do trabalho e como Dejours e Nietzsche percebem tragicamente o sofrimento, como inerente à vida, inevitável. Além disso, buscou entender como ambos percebem a utilização de defesas contra o sofrimento nessas organizações de trabalho e as estratégias defensivas contra o sofrimento, que podem trazer o equilibrio ou o desequilíbrio. E, por último, enfatizou a importância de profissionais críticos e de um espaço que facilite o processo de sofrimento como equilíbrio. A pesquisa adotou o método qualitativo, por meio de uma revisão de literatura, utilizando como referencial teórico a Psicodinâmica do Trabalho e a Filosofia. Identificou-se, com base nos autores estudados, que a dor e o sofrimento são inerentes ao trabalho e que ambos têm caráter constituinte na subjetividade dos trabalhadores.
\end{abstract}

Palavras-chave: sofrimento psíquico; estratégias defensivas; Nietzsche; Dejours.

\section{Defensive strategies against psychic suffering among workers}

\begin{abstract}
This article is meant to consist in a contribution towards worker's mental health understanding. To achieve this goal, we tried to briefly present, as background scenery, the context of work from a historical perspective. The expansion of the capitalist model, in the second half of the 20th century, engendered a progressive increase in the number of average working hours per worker and a continuous increase in time expenditure related to work issues, which seem to be issues that caused tangible effects on workers general health. This work has tried to pursue an evaluation of the successful worker profile, seeing suffering as a relatable presence in his or her working context and, as Dejours and Nietzsche tragically realize, in the understanding of suffering as an unavoidable and inherent feature of life. Besides that, the present article sought to understand precisely how these authors relate themselves with the perception of suffering within working organizational context and how they relate to defensive strategies aimed at mitigating it - which may bring dubious results given that they may either increase or decrease workers mental health condition. Finally, the present study emphasizes the importance of professionals capable of critical thinking and, also, of a working space that enables the perception of suffering process as a form of making mental health equilibrium achievable to the average worker. The research methods of choice were qualitative analysis review of bibliographic sources, and the adopted theoretical framework was technically related with literature in the fields of Psychodynamics of Work and Philosophy. The established result is that pain and suffering are meant to be understood as something inherent to every form of work activity that has a defining character in worker's subjectivity.
\end{abstract} Keywords: psychological distress; defensive strategies; Nietzsche; Dejours.

\section{Estrategias defensivas contra el malestar psicológico entre los trabajadores}

\section{Resumen}

El artículo estudia la contribución a la salud mental de los trabajadores. Para ello, buscamos, como antecedente, un breve contexto histórico de la obra. La expansión del modelo capitalista en la segunda mitad del siglo XX supuso un progresivo aumento del tiempo y una dedicación ininterrumpida al empleo, lo que repercutió en la salud de los trabajadores. Este trabajo evaluó el perfil del trabajador exitoso, el sufrimiento presente en el contexto laboral y cómo Dejours y Nietzsche perciben trágicamente el sufrimiento como inherente a la vida, inevitable. Además, se buscó comprender cómo se percibe tanto el uso de defensas contra el sufrimiento en estas condiciones laborales como las estrategias defensivas frente al sufrimiento, que pueden traer equilibrio o desequilibrio. Y, finalmente, destacó la importancia de los profesionales necesarios y un espacio que facilite el proceso de sufrimiento como equilibrio. La búsqueda adoptó el método cualitativo, a través de una revisión de la literatura, utilizando como marco teórico la Psicodinámica del Trabajo y la Filosofía. A partir de los autores estudiados, se identificó que el dolor y el sufrimiento son inherentes al trabajo y que ambos tienen un carácter constituyente en la subjetividad de los trabajadores.

Palabras clave: sufrimiento psíquico; estrategias defensivas; Nietzsche; Dejours.

\section{Introdução}

Os autores Jost, Fernandes e Soboll (2014) acreditam que enquanto existir o "trabalho vivo" existirão também

^Endereço para correspondência: Universidade Federal do Rio Grande do Sul Campus Litoral Norte. Rodovia RS 030, 11.700, km 92. Marechal Rondon Tramandaí, RS - Brasil. CEP: 95590-000 E-mails: wellington,amorim@gmail. com,afmouracarvalho@gmail.com,kelpsico2013@gmail.com

Os dados completos dos autores encontram-se ao final do artigo. os mecanismos de controle para adequar o trabalhador às necessidades do capitalismo. É possível constatar historicamente que a prática de controle da subjetividade humana está nas diversas formas de produção no cotidiano das 
organizações. A Revolução Industrial é um marco na mudança de como o indivíduo passou a ser visto no contexto do trabalho. O taylorismo, buscando uma maior produtividade, refletiu bem a divisão de tarefas, em um tempo determinado, em que o homem começou a ser visto como uma máquina de produção. Logo, o trabalho para o sujeito passou por um esvaziamento de sentido. Por outro lado, o fordismo, diferentemente do taylorismo, não contemplou apenas o interior das fábricas, mas se caracterizou pela produção e consumo em massa. O trabalhador se sentia valorizado, pois passou a receber melhor e, consequentemente, a ser um excelente consumidor. A subjetividade do trabalhador absorvia ideologias atreladas ao capitalismo, de maneira que, ao adentrar neste modo de produção, sentia-se incluso e reconhecido. O contexto do trabalho passou a controlar a vida do trabalhador para além das fábricas. A ideologia do progresso começou a embalar a produção em massa; o consumo era incentivado e a felicidade consistia no processo de sublimação oferecida pelo ato de consumir:

De acordo com Faria (2013), o intuito do fordismo era tirar o máximo que um trabalhador poderia executar, exercer o mais alto grau de controle sobre o processo de trabalho e de produção e controlar ao máximo a vida dos trabalhadores dentro e para além dos limites da fábrica por meio de mecanismos que furtavam a identidade, a cultura e a liberdade de pensar e agir (JOST; FERNANDES; SOBOLL, 2014, p. 55).

Vários fatores contribuíram para o declínio do padrão taylorista e fordista, substituído pelo modelo japonês toyotismo. Este novo modo de produção exigiu uma maior flexibilidade, levando o indivíduo a alterar sua autorreferência. Não existia estabilidade: a qualquer momento, desde que não cumprisse os moldes exigidos, o trabalhador seria demitido, substituído por vários outros indivíduos que gostariam de estar em seu lugar. A responsabilidade da produção passou a ser diretamente dos empregados, pois agora eram "colaboradores da empresa". Ao se esmiuçar o processo de transformação do mundo do trabalho, percebe-se que a subjetividade é pressionada por "ideologias do mundo moderno", como a exacerbação do individualismo, a intensificação do trabalho e o aumento do sofrimento psíquico: "Antunes (1997) afirma que o papel do Estado como mediador dos embates entre o trabalhador e o capital, num país como Brasil, e de resto nos denominados países semi-industrializados, sempre pareceu estar mais associado ao capital que ao trabalhador" (AQUINO, 2008, p. 176).

O Estado, que deveria primar pelo bem-estar de seus cidadãos, prioriza políticas de rentabilidade financeira e produtiva em detrimento do trabalhador. Goulart (2007) alerta que o processo de trabalho, quando adotado sob uma perspectiva macro, torna-se muito amplo e generalizante para o entendimento das relações particulares que se desenvolvem no interior das organizações para a realização do trabalho. A estrutura sociopolítica e econômica na qual as organizações estão inseridas constitui referência, mas não esgota as particularidades que se quer apreender no nível micro das organizações concretas. Desta maneira, este artigo tem por objetivo trazer uma breve contextualização histórica sobre o trabalho, analisar o perfil do trabalhador de sucesso, bem como o sofrimento psíquico e as estratégias defensivas no contexto do trabalho, a partir das reflexões de Nietzsche e Dejours.

\section{O perfil do trabalhador de sucesso: a ideologia da excelência}

Algumas noções de lazer estão interligadas ao ócio, mas o ócio é a atividade que traz em si a própria razão do seu fim. É o tempo dedicado a algo que traz uma experiência prazerosa e satisfatória, ocupação desejada, apreciada, escolha livre, satisfação ao vivenciá-lo, etc. Aquino e Martins (2007, p. 497) falam que "o ócio como experiência humana está relacionado a valores e significados profundos, apenas assim pode ter sentido como experiência significativa positiva, fonte de desenvolvimento e prevenção à ociosidade negativa, ou ócios nocivos". A palavra ócio traz valores negativos quando analisado pela influência religiosa puritana e pela história da industrialização e modernização. Todas duas detinham o poder e queriam, através de valores propositalmente difundidos, controlar o indivíduo até mesmo fora do tempo de trabalho. Logo, o tempo não dedicado ao trabalho era negativo (ócio), pois fazia desse homem menos rentável. O sujeito, aprisionado ao capitalismo, passa a subordinar-se aos dispositivos de lucros. O tempo livre agora é tenso, flexível, urgente, etc., ou seja, não é necessariamente livre.

Faria e Ramos (2014) falam especificamente como o "tempo de trabalho" ultrapassa o que formalmente lhe foi concedido e invade o "tempo livre", e como essa invasão do tempo livre pelo tempo de trabalho é construído também pela educação, em que o indivíduo desde criança aprende que o trabalho deve ocupar todos os espaços da vida do sujeito. Carrasqueira, Moraes e Soboll (2014) denunciam que o discurso do management gera uma rentabilização do ser humano em que a lógica empresarial é estendida à vida dos indivíduos. A existência humana passa a ser medida a partir do ideal de sucesso. Os autores analisaram discursos em matérias de destaques da $R e$ vista $S$. A., entre 2010 e 2011, e três pontos eram comuns no discurso das matérias: gerenciamento de carreira, flexibilidade e apelo psicológico exercido pelas organizações para que os "colaboradores" se comprometessem com as metas organizacionais. As três categorias se interrelacionam e cultuam o empreendorismo e a cultura do management em que o perfil do trabalhador de sucesso deixa o trabalho invadir outros aspectos de sua vida.

Saraiva e Mendes (2014) denunciam em nível macro a forma de funcionamento das organizações em que através do "pensamento único" se difunde a ideologia de que toda a economia só tem um caminho, a globalização, da qual ninguém pode escapar, todos estão predestinados a competir e somente o melhor sobreviverá. Mas ser empreendedor, ser o melhor, o primeiro, superar a si mesmo e a outros requer que alguém fique de fora. Cria-se uma nova subjetividade, que passa a perceber que a excelência é o sentido de sua vida. Para uma existência feliz e bem-sucedida, depende da lógica da competitividade, do individualismo, do empreendorismo, da meritocracia, da autossuperação, etc. A excelência prega que a felicidade 
depende apenas da vontade e esforços empenhados, ser capaz de assumir riscos e de superar-se sempre. Por meio de um "deslocamento de sentido", o trabalhador acredita que está realizando projetos de interesse pessoal e que sua subjetividade está em busca de reconhecimento se colocando a serviço do lucro. Não há lugar para o fracasso. Não é mais preciso uma vigilância de perto das organizações, o próprio sujeito se autovigia, fazendo exatamente o que a organização propõe. No entanto, a padronização da subjetividade pode ser nociva. Os desdobramentos podem ser observados nas descompensações psíquicas, na solidão, nos assédios morais, nas violências, nas patologias decorridas do desgaste do trabalho, etc.

Para Silva (2011), o individualismo, a competitividade a qualquer custo, a flexibilidade, etc. aumentam a desconfiança e a insensibilidade relacionadas a todos que dividem o espaço de convivência no trabalho. As organizações incentivam todas essas inversões de valores humanos com o propósito de deixar o sujeito mais "adaptado" ao perfil ideal de funcionário. A organização quer alguém que abrace os ideais de sua empresa, mesmo que para isso precise criar ideais existenciais imprescindíveis ao trabalhador. Por isso a subjetividade e seu desgaste psíquico se contextualizam nas relações de poder. A cultura da excelência, que traz uma ideia de perfeição a ser alcançada por todos, contribuiu diretamente para agravar os problemas de saúde física e psíquica dos trabalhadores. Tal ideologia começa na seleção, passando pelo treinamento e por outros processos organizacionais, escondendo uma relação de subordinação a qualquer custo, em que nem mesmo o adoecer se torna um obstáculo. Para alcançar a ideologia da excelência, o homem se submete a ambientes e situações degradantes, sendo incentivado constantemente a ser um excelente colaborador, não importando se já passou do horário de expediente ou se está com sua família ou em um momento de lazer.

Ela [a ideologia da excelência] também naturaliza e banaliza a exploração, tornando-a consentida por meio da mobilização da subjetividade para o alcance dos objetivos organizacionais. Impõe também o culto ao autoempreendedorismo, ao individualismo e à manutenção de uma falsa cooperação pela prática da competição de todos contra todos, ainda que trabalhando em equipe. Propõe também a superação de metas individualizadas, a autossuperação, a responsabilidade pelos riscos assumidos, a ter a obrigação de vencer e de ser o melhor, tornando-o prisioneiro de sua própria condição de trabalhador em busca de sucesso (SOBOLL; HORST, 2013, p. 230).

Silva (2011) chama a atenção para a existência de uma violência social e como esta se apresenta no contexto laboral. Os trabalhos que colocam os indivíduos em situação de risco, atingindo seu organismo, com certeza também atingirá seu psíquico; sendo difícil, portanto, cindir o ser humano em sua existência. $\mathrm{O}$ autor nos alerta que a subjetividade é influenciada pela ideologia da excelência, passando a ser determinante no direcionamento dos processos que conduzem ao adoecimento mental e ao desequilíbrio psicossomático, entre outras patologias.

Sofrimento psíquico no contexto do trabalho empresarial
Dejours e Abdoucheli (1994) abordam a análise dinâmica dos processos psíquicos mobilizados pela confrontação do sujeito com a realidade do trabalho. Logo, percebem que, além da psicopatologia da vida cotidiana e do trabalho, existe uma psicopatologia da normalidade. Primeiramente, as pesquisas só relacionavam o contexto do trabalho com afecções mentais. Lentamente evidenciaram-se as condições psicológicas do trabalho e suas consequências para a saúde, em que, ao invés das doenças mentais clássicas, as pesquisas passaram a apontar a eclosão de doenças no corpo pela "fragilização". Tais mudanças surgiram, entre outras causas, pela mudança de comportamento do trabalhador, que se tornou mais ativo em seus processos de trabalho, rompendo com uma perspectiva mais submissa diante das pressões e exigências organizacionais, o que acarretou impactos à saúde física e mental relacionados ao trabalho.

Diante do exposto, os adoecimentos físicos e o sofrimento psíquico passaram a ser mais fortemente associados aos efeitos laborais. O sofrimento patológico emerge quando a relação subjetiva com o trabalho está bloqueada e o sujeito já esgotou todas as tentativas de adaptação à organização. Uma luta contra uma força ligada às organizações do trabalho que o empurram em direção a uma descompensação (mental ou psicossomática) e para a doença. $\mathrm{O}$ assédio moral que causa o sofrimento no trabalhador caracteriza-se pelo ataque contra a dignidade do sujeito, de maneira repetitiva por um período de tempo. Pode ser feita por um superior, ou por alguém de mesmo nível hierárquico, a uma pessoa ou a um grupo de empregados. A própria organização comete assédio moral com seus funcionários quando os submete a metas impossíveis, a sobrecarga de trabalho, a locais insalubres, a humilhações, etc.

$\mathrm{O}$ isolamento social que pode surgir como resposta ao sofrimento causa um gradual retraimento que pode culminar em um isolamento ainda maior, inclusive em ambientes fora do trabalho, como por exemplo no relacionamento com amigos e família. A irritabilidade que, segundo Silva (2011), merece maior atenção, já que aparece como peça no contexto do adoecimento. O mal-estar no contexto laboral pode suscitar no sujeito uma fuga para o alcoolismo ou uso de outros entorpecentes que causam dependência. $O$ transtorno de estresse pós-traumático, quadros depressivos, suicídios, a ansiedade e outras constatações de adoecimento são explanados pelo autor, que os relacionam ao assédio e ao modo como ele é vivenciado pelo sujeito que sofre.

\section{Utilização de estratégias defensivas contra o sofrimento psíquico: possível fator de equilíbrio e desequilíbrio}

Ao se falar em estratégias defensivas é necessário contextualizar o conceito de sofrimento psíquico. Para Dejours e Abdoucheli (1994), é um conceito possuidor de uma fonte empírica e dinâmica e uma consistência teórica e metapsicológica em que existe uma lógica essencialmente defensiva ou essencialmente criativa. Logo, o sofrimento é trágico, inevitável e ambíguo.

O desafio real na prática, para a psicologia do trabalho, é definir as ações suscetíveis de modificar o destino do so- 
frimento e favorecer sua transformação (e não sua eliminação). Quando o sofrimento pode ser transformado em criatividade, ele traz uma contribuição que beneficia a identidade. Ele aumenta a resistência do sujeito ao risco de desestabilização e da fragilização da saúde. O trabalho funciona como um mediador para a saúde. Quando, ao contrário, a situação de trabalho, as relações sociais de trabalho e as escolhas gerenciais empregam o sofrimento no sentido de sofrimento patogênico, o trabalho funciona como mediador da desestabilização e da fragilização da saúde (DEJOURS; ABDOUCHELI, 1994, p. 137).

Parece que nesse momento o sofrimento é visto como inerente ao ser humano. Da mesma maneira como Nietzsche percebe a existência. Uma eterna luta em que a subjetividade se expressa ambiguamente, sempre entre o apolíneo e o dionisíaco, que em alguns momentos apresenta-se diante de uma confrontação (auseinandersentzung) e, em outros momentos, busca uma conciliação:

A seus dois deuses da arte, Apolo e Dionísio, vincula-se a nossa cognição de que no mundo helênico existe uma enorme contraposição, quanto a origens e objetivos, entre a arte do figurador plástico [Bildner], a apolínea, e a arte não figurada da música [unbildlichen], a de Dionísio: ambos os impulsos, tão diversos, caminham lado a lado, na maioria das vezes em discórdia aberta e incitando-se mutuamente a produções sempre novas, para perpetuar nelas a luta daquela contradição sobre a qual a palavra comum "arte" lançava apenas aparentemente ponte; até que, por fim, através de um miraculoso ato metafísico da "vontade" helênica, apareceram emparelhados um com o outro, e nesse emparelhamento tanto a obra de arte dionisíaca quanto a apolínea geraram a tragédia ática (NIETZSCHE, 2007, p. 24).

O pensamento de Nietzsche consiste na afirmação ativa da dor que é parte integrante da vida, estando em uma eterna confrontação e não podendo ser evitada. Quando o indivíduo consegue afirmar a dor alegremente, ele pode viver a existência em sua integralidade, através de uma sabedoria alegre. Dizer sim à vida, mesmo diante do sofrimento, afirmando-a em todos os seus momentos, não é uma tarefa para muitos, são poucos os que assumem a posição de um niilista ativo, possibilitando a afirmação da vida na transvaloração da dor. Somente desta forma, segundo Nietzsche, é que o homem deixará de ser um meio para ser um além-homem (Übermensch). Zaratustra nos ensina uma terapêutica, ou melhor, como se pode ser senhor de si mesmo, apesar da dor e sofrimento. Dor e sofrimento são partes da vida e viver é um processo de contínua libertação. Pode-se experienciar muitas coisas: morte, amor, raiva, alegria, mas é perante os obstáculos que o homem se mostra como um guerreiro que se supera, para enfim tornar-se um além-homem.

Nietzsche nos convoca a nos tornamos nós mesmos. Esta é a verdadeira terapêutica: tornar-se o que se é. Logo, o homem é responsável por sua vida; deve assumir que todo tipo de sofrimento faz parte do existir, não há possibilidade de não sofrer, é um processo natural do mundo, tudo muda, tudo deixa de ser, um eterno devir, transitoriedade: o que não deixa de ser é porque nunca foi. O homem fraco se ressente eternamente pelo que ele não foi, porque de fato não construiu seu comportamento diante de suas vivências, simplesmente repete comportamentos aceitos socialmente (construídos para algum fim), sem com isso necessariamente ter aprendido algo, ou ter amadurecido. O homem se torna ressentido sofrendo psicologicamente em seus pesares e se justificando para não agir conforme gostaria, se sacrificando, negando seu desejo.

Dejours, Dessors e Desriaux (1993) afirmam que a doença física se desencadeia por uma situação afetiva insustentável. A saúde mental é a existência da esperança, das metas, dos objetivos que podem ser elaborados. É quando há o desejo. O que faz as pessoas viverem é o desejo e não só as satisfações. $O$ verdadeiro perigo é quando o desejo não é mais possível, podendo o indivíduo adoecer diante dessa impossibilidade. Ao laborar, o homem acumula uma energia psíquica (tensão nervosa) a qual não pode ser sublimada, repreendida ou retida. $\mathrm{O}$ trabalhador precisa de um escoamento conveniente à sua energia psíquica. $\mathrm{O}$ bem-estar psíquico está diretamente relacionado ao livre funcionamento em relação ao conteúdo da tarefa (trabalho livremente escolhido e organização do trabalho harmonioso).

Logo, Nietzsche (2007) e Dejours (2004) falam de um sofrimento psíquico que é inerente à vida e que pode adoecer o homem, ou ser transformado, transvalorado, para uma dor ativa ou um sofrimento criador. Os estudos de Dejours e Abdoucheli (1994) mostram que as estratégias de defesa podem ser usadas frente ao sofrimento nas organizações de forma individual ou coletiva. As individuais minimizam a percepção das pressões patogênicas sofridas; as coletivas contribuem para assegurar a coesão e a construção do coletivo de trabalho e, através de um consenso, funcionam como regras e conferem ao sujeito uma estabilidade que ele não conseguiria garantir apenas com suas defesas individuais.

Dejours e Abdoucheli (1994) nos trazem como exemplo estratégias defensivas coletivas, a indiferença de todos diante de uma comunicação distorcida que frustrou e retirou o sentimento de esperança; e, como individuais, a valorização das vivências fora do trabalho, pela sublimação, que é um comportamento inteligente, nem sempre consciente, e que ajuda na sobrevivência dos obstáculos. O trabalho no qual a organização dá pouca importância ao desejo pode levar o indivíduo ao adoecimento, mas o trabalho também pode ser um mediador de autorrealização, sublimação e saúde, quando leva o indivíduo ao caminho de um sofrimento criativo. Nietzsche (2007), tanto no contexto de trabalho como em outros contextos, observa que alguns indivíduos se ressentem diante da dor, o que pode ocasionar o sofrimento e o adoecimento humanos, mas ele também observa que outros vivem afirmativamente a vida, estando mais próximo do que se é, e não seguindo valores distantes de si. O homem é vontade e isso não pode ser mudado. A natureza não busca algo fixo, ela se transforma todo o tempo, e nesta metamorfose pode ocorrer a construção de novos valores, por consequência, um além-homem (Übermensch). 


\section{Conclusão}

É necessário um espaço de escuta para a manifestação do sofrimento, para que o trabalhador possa falar sobre o que sente, possibilitando, dessa maneira, diversos benefícios para a sua saúde, como: felicidade em participar do trabalho, níveis reduzidos de absenteísmo, menos acidentes, cooperação de proteção mútua, etc. $\mathrm{O}$ entendimento é possível e desejável, e deste modo o processo de reestruturação organizacional pode exigir que o sujeito se mantenha aberto, sem medo das transformações, que corra riscos com otimismo e, sobretudo, expresse satisfação com a vida. Para Nietzsche (2007) a dor não é uma experiência necessariamente ruim. $\mathrm{O}$ utilitarismo da ciência, que tenta abolir o desprazer, se equivoca ao tentar abolir algo inerente ao homem, e desta maneira propõe, como contraponto, o conhecimento alegre, a sabedoria aliada ao riso e a uma sensação de júbilo que só é possível quando a dor se encontra enlaçada ao prazer. A dor é percebida como um caminho que pode tornar os homens mais fortes. $\mathrm{O}$ homem moderno precisa da experiência da dor, que tem o caráter de uma "formação", ou ainda, de transformação. A busca incessante pela ausência de dor tem como consequência uma aversão à dor. $\mathrm{O}$ sofrimento dos tempos da modernidade se traduz em uma espécie de hipersensibilidade e intolerância à dor, e o remédio proposto para este "mal" parece ser paradoxal: "A melhor receita para a miséria é a própria miséria” (NIETZSCHE, 1974, p. 125).

Neste ponto, encontramos uma ressonância com a travessia da dor em Dejours, Dessors e Desriaux (1993), processo que requer o encontro necessário com o próprio sofrimento para uma possível mudança. Estes autores situam o trabalho como possível fator de equilíbrio, em que é possível ao sujeito buscar um trabalho que possua sentido, um oficio que vá além do modo de ganhar a vida, que represente uma parte importante do viver, que, mesmo sendo um fator de deterioração e desgaste, também seja essencial para o equilíbrio e desenvolvimento do sujeito. A busca da saúde é algo dinâmico, um objetivo a ser alcançado, sendo difícil chegar a um completo bem-estar. O organismo não é estático, mas em perpétuo desequilíbrio e retorno ao equilíbrio, reforçando, dessa maneira, um aspecto positivo, ao afirmar que o sujeito pode escolher seu modo operatório ou modificá-lo. Com base no exposto, as análises realizadas no presente artigo buscaram contribuir para as articulações entre a subjetividade do trabalhador, o sofrimento psíquico no trabalho, as estratégias defensivas e os impactos do trabalho na saúde mental do trabalhador à luz do recorte teórico das teorias dejouriana e nietzschiana.

\section{Informações sobre os autores:}

\section{Wellington Lima Amorim \\ (iD) https://orcid.org/0000-0002-7299-410X \\ (9) http://lattes.cnpq.br/8435602742904295}

Possui pós-doutorado em Filosofia pela UFRJ; pós-doutorado em Desenvolvimento Regional pela Universidade do Contestado (2018); doutorado Interdisciplinar em Ciências Humanas pela Universidade Federal de Santa Catarina (2009); mestrado em Filosofia pela Universidade do Vale do Rio dos Sinos (2005) e especialização sobre o Ensino de Filosofia pela Universidade do Vale do Rio dos Sinos (2005). É bacharel em Filosofia pela Universidade Federal do Rio de Janeiro (2003) e realizou o Curso Superior de Tecnologia em Construções Militares (1993). Atuou como professor visitante na Universidade de Barcelona de 2009 a 2011. Atualmente atua como professor e coordenador do projeto de pesquisa intitulado "Estado, Sociedade e Desenvolvimento: é possível pensar em uma filosofia do desenvolvimento regional?", pela Universidade Federal do Rio Grande do Sul.

\section{Ana Flávia Moura Carvalho}

(iD) https://orcid.org/0000-0003-2230-0568

(9) http://lattes.cnpq.br/2973863347119078

Possui graduação em Psicologia pela Universidade Federal do Maranhão (2006) e mestrado pelo Programa de Pós-graduação em Psicologia pela Universidade Federal do Maranhão (2018). Atualmente é docente na Universidade Ceuma, em São Luís, Maranhão. Tem experiência em Psicologia na Assistência Social, Psicologia da Saúde e Psicologia Organizacional e do Trabalho, com ênfase na saúde do trabalhador.

\section{Rachel Vianna Leão \\ (iD) https://orcid.org/0000-0003-4382-8812 \\ (9) http://lattes.cnpq.br/4120667775600524}

Possui graduação em Psicologia pela Faculdade Frassinetti do Recife (2004) e mestrado pelo Programa de Pós-graduação em Psicologia pela Universidade Federal do Maranhão (2017). Atualmente é psicóloga na Secretaria Municipal da Criança e Assistência Social, psicoterapeuta e professora no Centro Universitário Maurício de Nassau, (UNINASSAU), em Aracaju. Tem experiência na área da Docência, Psicologia Social, Psicologia na Assistência Social, Psicologia Clínica e Psicologia de Tráfego, com ênfase no indivíduo e em suas relações sociais.

\section{Contribuições dos autores:}

Todos os autores colaboraram ao longo do processo, desde a elaboração até a revisão final do manuscrito. Os autores aprovaram o texto final para publicação.

\section{Como citar este artigo:}

\section{ABNT}

AMORIM, Wellington Lima; LEÃO, Rachel Vianna; CARVALHO, Ana Flavia Moura. Estratégias defensivas contra o sofrimento psíquico entre trabalhadores. Fractal: Revista de Psicologia, Niterói, v. 33, n. 3, p. 199-204, set./dez. 2021. https:// doi.org/10.22409/1984-0292/v33i3/5899

\section{APA}

Amorim, W. L., Leão, R. V., \& Carvalho, A. F. M. (2021, Setembro/ Dezembro). Estratégias defensivas contra o sofrimento psíquico entre trabalhadores. Fractal: Revista de Psicologia, 33(3), 199-204. doi: https://doi.org/10.22409/1984-0292/v33i3/5899

\section{Copyright:}

Copyright (C) 2021 Amorim, W. L., Leão, R. V., \& Carvalho, A. F. M. Este é um artigo em acesso aberto distribuído nos termos da Licença Creative Commons Atribuição que permite o uso irrestrito, a distribuição e reprodução em qualquer meio desde que o artigo original seja devidamente citado.

Copyright (C 2021 Amorim, W. L., Leão, R. V., \& Carvalho, A. F. $M$. This is an Open Access article distributed under the terms of the Creative Commons Attribution License, which permits unrestricted use, distribution, and reproduction in any medium, provided the original article is properly cited. 


\section{Referências}

AQUINO, Cassio Adriano Brás de. O processo de precarização laboral e a produção subjetiva: um olhar desde a psicologia social. O Público e o Privado, v. 6, n. 11, p. 169-178, 2008. Dossiê Mundo do Trabalho. Disponível em: https://revistas. uece.br/index.php/opublicoeoprivado/article/view/2383. Acesso em: 4 out. 2020.

AQUINO, Cassio Adriano Brás de; MARTINS, José Clerton de Oliveira. Ócio, lazer e tempo livre na sociedade do consumo e do trabalho. Revista Mal-estar e Subjetividade, Fortaleza, v. 7, n. 2, p. 479-500, set. 2007. Disponível em: https://periodicos. unifor.br/rmes/article/view/1595/3577. Acesso em: 19 maio 2020.

CARRASQUEIRA, Flora; MORAES, Rafaela Mayer; SOBOLL, Lins Andrea. Desejo de carreira, flexibilidade e engajamento: o perfil do trabalhador de sucesso na cultura do management. In: SOBOLL, Lins Andrea; FERRAZ, Deise Luiza da Silva (Org.). Gestão de pessoas: armadilhas da organização do trabalho. São Paulo: Atlas, 2014. p. 216-232.

DEJOURS, Christophe. Entre sofrimento e reapropriação: o sentido do trabalho. In: LANCMAN, Selma; SZNELWAR, Laerte Idal (Org.). Christophe Dejours: da psicopatologia à psicodinâmica do trabalho. Rio de Janeiro: Paralelo 15; Fiocruz, 2004. p. 303-316.

DEJOURS, Christophe; ABDOUCHELI, Elisabeth. Itinerário teórico em psicopatologia do trabalho. In: DEJOURS, Christophe; ABDOUCHELI, Elisabeth; JAYET, Chrístian (Org.). Psicodinâmica do trabalho: contribuições da escola dejouriana à análise da relação prazer, sofrimento e trabalho. São Paulo: Atlas, 1994. p. 119-145.

DEJOURS, Christophe; DESSORS, Dominique; DESRIAUX, François. Por um trabalho, fator de equilíbrio. Revista de Administração de Empresas, São Paulo, v. 33, n. 3, p. 98-104, 1993. https://doi.org/10.1590/S0034-75901993000300009

FARIA, José Henrique de; RAMOS, Cíntia Letícia. Tempo dedicado ao trabalho e tempo livre: os processos sóciohistóricos de construção do tempo de trabalho. RAM, Revista de Administração Mackenzie, São Paulo, v. 15, n. 4, p. 47-74, 2014. https://doi.org/10.1590/1678-69712014/administracao. v15n4p47-74

GOULART, Irís Barbosa. Psicologia do trabalho e gestão de recursos humanos: estudos contemporâneos. São Paulo: Casa do Psicólogo, 2007.

JOST, Rossana; FERNANDES, Bruna; SOBOLL, Lis Andrea. A subjetividade do trabalhador nos diversos modelos de gestão. In: SOBOLL, Lis Andrea; FERRAZ, Deise Luiza da Silva (Org.). Gestão de pessoas: armadilhas da organização do trabalho. São Paulo: Atlas, 2014. p. 48-66.

NIETZSCHE, Friedrich (1881-1882). A gaia ciência. In: Obras Incompletas. São Paulo: Victor Civita, 1974. Coleção Os Pensadores. p. 195-231.

NIETZSCHE, Friedrich. O Nascimento da Tragédia, ou Helenismo e Pessimismo. Tradução, notas e posfácio de Jacó Guinsburg. São Paulo: Companhia das Letras, 2007.

SARAIVA, Luiz Alex Silva; MENDES, Ana Magnólia. Consultores de mercado, sua lógica perversa de gestão e normopatia. Revista Polis e Psique, v. 4, n. 1, p. 128-145, 2014. https://doi.org/10.22456/2238-152X.42769
SILVA, Edith Seligman (Org.). Psicopatologia da violência e suas expressões clínicas. In: Trabalho e desgaste mental: o direito de ser dono de si mesmo. São Paulo: Cortez, 2011. p. 492-550.

SOBOLL, Lis Andrea; HORST, Ana Carolina. Ideologia da excelência. In: VIEIRA, Fernando Oliveira; MENDES, Ana Magnólia; MERLO, Alvaro Roberto Crespo (Org.). Dicionário crítico de gestão e psicodinâmica do trabalho. Curitiba: Juruá, 2013. p. 225-230. 